\title{
The development of a broccoli supplemented beer allows oc obtaining a valuable dietary source of sulforaphane
}

i) The corrections made in this section will be reviewed and approved by a journal production editor.

QS

Q1

aPhytochemistry and Healthy Food Lab., Research Group on Quality, Safety, and Bioactivity of Plant Foods.

Department of Food Science and Technology, CEBAS-CSIC, Campus Espinardo, 25, 30100, Espinardo, Murcia, Spain

${ }^{\text {b} D e p a r t m e n t ~ o f ~ F o o d ~ T e c h n o l o g y, ~ E P S O, ~ U n i v e r s i t y ~ M i g u e l ~ H e r n a ́ n d e z, ~ C t r a . ~ B e n i e l ~ k m . ~ 3.2, ~ 03312, ~ O r i h u e l a, ~}$ Alicante, Spain

${ }^{*}$ Corresponding author.

\begin{abstract}
Beer is a popular fermented beverage made, basically, by water, malted cereals, yeasts, and hops. However, the actual market demands innovative beers with new nutritional and organoleptic properties, achieved, for instance, by the addition of functional ingredients. In this hallmark, the objective of this work was to elaborate a new beer enriched with broccoli florets as a source of bioactive compounds, potentially contributing to human health. As a result, the newly developed broccoli-supplemented beverage exhibited high concentrations of the bioactive isothiocyanates as sulforaphane (SFN) $(18.85 \mu \mathrm{mol} / \mathrm{L})$, while the inactive glucosinolate precursor (glucoraphanin (GR) was not detected. In addition, during the 150 days storage, SFN was almost stable, just evidencing a slight but significant decrease, reaching a final concentration of $0.80 \mu \mathrm{mol} / \mathrm{L}$. Besides, the alternative developed beer showed an acceptable sensorial profile. Thus, the present work describes the design and development of a new broccoli-supplemented beer that would constitute a valuable dietary source of health promoting SFN.
\end{abstract}

Keywords: Brassica oleracea; Glucosinolates; Isothiocyanates; Added-value beverage; Functional ingredient; Bioactive compounds

Abbreviations: ESI, electro spray ionization; GAE, gallic acid equivalents; GLS, glucosinolates; GR, glucoraphanin; ITC, isothiocyanates; RP-HPLC, reversed phase high performance liquid chromatography; SFN, sulforaphane

\section{Introduction}

Beer is one of the most widely consumed beverage, mainly constituted by water, malted cereals, yeasts, and hops ( Gresser, 2009, pp. 359-397). Thus, combining different factors allows designing and producing a wide diversity of beer types, like Ale or Lager (Papazian, 2009, pp. 41-74). According to data available from the Spanish Beer Socioeconomic sector, the industrial production of beer has raised through the last ten years to reach almost $38 \times 10^{6} \mathrm{hl}$ per year -(STATISTA, 2020). These beverages usually display a wide diversity of colors and organoleptic characteristics, mainly due to the ingredients used for the distinct beers and the content of compounds produced during the fermentation process (Albaladejo et al., 2017; Kyselová \& Brányik, 2015, pp. 477-500; Vera et al., 2011). According to the nutritional and non-nutritional composition of beer ingredients, bioactive nutrients (vitamins, minerals, 
carbohydrates, and amino acids, among others) and non-nutrients (mainly phenolic compounds), this beverage could be considered on its potential health benefits, as anti-inflammatory and antioxidant effects (Humia et al., 2019; Md Salim et al., 2019).

The referred increase of beer production is a result of the market demand, which nowadays is favored by the wide range of beers available, being relevant the new craft beers that has increased the production and consumption in countries like Italy, Spain, France or Mexico (Carvalho et al., 2018). In this aspect, the market demands more and more variety and quality, as well as healthier products that would contribute to human wellbeing. Thus, the nutritional and

Q2 organoleptic quality depends on an array of factors including diverse manufacturing conditions (Caporale \& Monteleone, 2004), the yeast strains employed and the characteristics of the fermentation process (Capece et al., 2018), the type of cereals or seeds, and the ethanol grade (Bellut et al., 2019). Besides these factors, directly and closely related to beer quality, the use of new ingredients, conferring to beer distinguishing characteristics, has prompted to evaluate the possibility of including in the beer manufacturing process functional ingredients that could provide valuable biological activities (Humia et al., 2020).

In relation to the use of functional (health-promoting) ingredients for the development of new types of craft beers, broccoli (Brassica oleracea) is an interesting source of both nutritional (vitamins and minerals) and non-nutritional (phenolic compounds, glucosinolates (GLS), and isothiocyanates (ITC)) bioactive compounds (Ramirez et al., 2020). Indeed, this brassica-food has been successfully used in the development of functional products as an ingredient donor of bioactive compounds (Alvarez-Jubete et al., 2014; Dominguez-Perles et al. 2011, Dominguez-Perles et al. 2012; Totušek et al., 2011). Regarding this fact, diverse health benefits have been associated to bioactive compounds present in this plant-based food, but the radical scavenging activities of different compounds is depended on their structure ( Dimitrić Marković et al., 2017; Koh et al., 2009; López-Chillón et al., 2018). The most characteristic class of phytochemicals in brassica-foods are sulfur-containing compounds, known as glucosinolates (Abellán et al., 2019). However, these are non-bioactive compounds, as they need to be metabolized into the bioactive ITCs by the enzyme myrosinase. This enzyme is released from the vacuoles, present in plant cells, after damages that affect the integrity of the cell membrane (Baenas et al., 2017). Glucoraphanin (GR) and sulforaphane (SFN) are the most abundant GLS and ITC in broccoli, respectively (Dominguez-Perles et al., 2011), being characterized by a range of biological activities that could enhance the healthy attributions of beer (Bertuzzi et al., 2020).

Due to these antecedents, the present study deals with the design of a novel craft beer using broccoli as an ingredient, source of bioactive compounds. As far as we are aware, this is the first report were a beer is enriched with broccoli and characterized on the content of SFN, thus obtaining a new product as a valuable source of bioactive compounds.

\section{Materials and methods}

\subsection{Plant material}

Broccoli (Brassica oleracea L var. Italica, cv 'Parthenon') heads were obtained from a commercial grower in Murcia (Spain). The inflorescences (marketable-mature heads) were transported immediately to the laboratory, under cold conditions, after harvest.

\subsection{Beers brewing}

Preliminary analyses lead to select $10 \%$ addition of broccoli to beer $(\mathrm{w} / \mathrm{v})$ as the best ratio for the study, due to its limited impact on the organoleptic properties of beer, observed by a trained panel (see below).

After defining the weight of broccoli, a broccoli-supplemented American amber ale type beer was elaborated ( 3 batches of $25 \mathrm{~L}$ ). The malts used for brewing were Pale ale $83.9 \%$ (as base malt), Cara-Crystal 10.8\%, and Carafa 5.3\% (special malts), all of them from Weyermman $\odot$ (Bamberg, Germany). These were mashed at $72{ }^{\circ} \mathrm{C}$ during $1 \mathrm{~h}$. The boiling was carried out for $60 \mathrm{~min}$, and the hops were added at 0 and 30 min regarding Chinook $(1.16 \mathrm{~g} / \mathrm{L})$ and Centennial $(0.83 \mathrm{~g} / \mathrm{L})$, respectively. After cooling $\left(25^{\circ} \mathrm{C}\right)$, fermentation took place with Safale US-05 (Fermentis, Marcq-en-Baroeul, France) yeast during 10 days until the density of the beer dropped to $1.010 \mathrm{~g} / \mathrm{L}$. Then, the inflorescences (previously disinfected with $100 \mathrm{ppm}$ of sodium hypochlorite and rinsed three times with distilled water) were added and mixed with the brewed beer at the ratio broccoli/beer $(10: 90, \mathrm{w} / \mathrm{v})$ and left to macerate for 3 days, at $10{ }^{\circ} \mathrm{C}$. Afterward, the broccoli heads were removed from the beer by racking, using a filter mesh, and the beers were 
maintained in the fermentation tanks until the fermentation process finished (day 14 ), at $10{ }^{\circ} \mathrm{C}$. Then, the broccolisupplemented beers were introduced into glass amber beer bottles $(330 \mathrm{~mL}$ capacity) and were stored under room temperature $\left(25-30^{\circ} \mathrm{C}\right)$ for 2 weeks, prior to analysis of physico-chemical parameters and sensory evaluations. In order to study the presence of GR and SFN, during shelf life, bottled beers $(330 \mathrm{~mL}$ amber glass bottle) were stored at room temperature during 5 months, and samples were taken each month for analytical purposes.

\subsection{Physico-chemical parameters of beer}

Total soluble solids (TSS), total acidity (TA), $\mathrm{pH}$, alcoholic grade (\% v/v), color (EBC), and bitterness (IBUs) were determined as physico-chemical parameters in control and broccoli beer. The samples from three bottles were analyzed in duplicate.

The TSS, expressed as ${ }^{\circ}$ Brix, and $\mathrm{pH}$ were measured by using a digital refractometer Atago PR-101 (Atago Co. Ltd., Tokyo, Japan) at $20^{\circ} \mathrm{C}$, and a pH meter GLP 21 (Crison Instruments S.A., Barcelona, Spain), respectively. Total acidity (TA) was measured by automatic titration (785 DMP Titrino, Methohm) with $0.1 \mathrm{~N} \mathrm{NaOH}$ up to $\mathrm{pH} 8.1$, using $1 \mathrm{~mL}$ of beer in $25 \mathrm{~mL}$ of distilled $\mathrm{H}_{2} \mathrm{O}$, and results were expressed as \% lactic acid (g lactic acid equivalent per $100 \mathrm{~mL})$.

Alcoholic grade was calculated by using the density data of the beers, which were obtained with a hydrometer (Stevenson Reeves, Ltd.) before and after fermentation.

Color EBC and Bitterness were determined according with the Official Methods of the Analytical Division of European Brewery Convention, EBC Method 9.6 and 9.8, respectively, using a spectrophotometer (UV-2401 PC spectrophotometer, Shimadzu, Kyoto, Japan) (Zapata et al., 2019).

\subsection{Extraction and HPLC-DAD-ESI-MSn analysis of glucosinolates in plant material}

The extraction and chromatographic analysis (HPLC-DAD) of GLS present in the broccoli heads, used to supplement the newly developed beer, were carried out according to Baenas et al. (2019). Briefly, for analytical purposes, broccoli heads were cut into small pieces and mixed thoroughly, to be bulked again into 3 well-mixed replicates $(n=3)$. The samples were then flashfrozen using liquid nitrogen and kept at $=-80{ }^{\circ} \mathrm{C}$ until being freeze-dried (Christ Alpha 1-4D, Christ, Osterode am Harz, Germany). Once lyophilized the samples were ground to a fine powder and stored at $=-20^{\circ} \mathrm{C}$ for further analysis.

With respect to the extraction procedure, samples $(100 \mathrm{mg})$ were extracted with $1 \mathrm{~mL}$ methanol/deionized water (70:30, $\mathrm{v} / \mathrm{v}$ ) during $30 \mathrm{~min}$, at $70{ }^{\circ} \mathrm{C}$, being vortexed each $5 \mathrm{~min}$ to improve the efficiency of the extraction process using a vortex stirrer. Then, the samples were cooled in ice and subsequently centrifuged at $17500 \mathrm{~g}$ for $12 \mathrm{~min}$. The supernatant was collected and extraction solvent removed using a rotary evaporator. The dried residue was reconstituted in $1 \mathrm{~mL}$ of deionized-water and filtered through a $0.2 \mu \mathrm{m}$ inorganic membrane filter (ANOTOP 10 plus, Whatman, Maidstone, U.K.).

After suspending the samples in $1 \mathrm{~mL}$ deionized-water, GLS were first tentatively identified according to their parent mass $\left(m / z[\mathrm{M}-\mathrm{H}]^{-}\right)$, specific fragmentation pattern $\left(\mathrm{m} / z\right.$ MS2 $\left.[\mathrm{M}-\mathrm{H}]^{-}\right)$and DAD patter, and retention time and order of elution (Francisco et al., 2009). The chromatographic separation and spectrometric analyses developed for the identification of the target GLS were achieved by Reverse Phase High Performance Liquid Chromatography (RPHPLC) consisting of a diode array detector (DAD) coupled to mass spectrometer (MS) using Electro spray ionization (ESI) in negative mode for the analyses (HPLC-DAD-ESI-MSn Agilent Technologies, Waldbronn, Germany). Once identified, GLS were quantified using an HPLC-DAD 1260 Infinity Series (Agilent Technologies, Waldbronn, Germany) method in accordance with the order of elution already described for the identification and $\mathrm{UV}_{=-}$vis characteristic spectra. The chromatographic separation of GLS was achieved in a Luna C18 100A column $(250 \times 4.6 \mathrm{~mm}, 5 \mu \mathrm{m}$ particle size; Phenomenex, Macclesfield, UK), using the solvents deionized-water/trifluoroacetic acid (optima LC/MS from FisherScientific Co., Fair Lawn, NJ, US) (99.9:0.1, v/v) (A) and acetonitrile (LC-MS-grade quality from HiPerSolvChromanorm, BDH Prolabo, Leuven, Belgium) (B), and applying the following linear gradient (time, \%B), (0, 1\%); (15, 17\%); (17,17\%); (22, 25\%); (30, 35\%); and $(35,50 \%)$. The later percentage of solvents was maintained up to $45 \mathrm{~min}$ for column equilibration purposes. The flow rate and volume of injection were $1 \mathrm{~mL} / \mathrm{min}$ and $10 \underline{\mu} \mu \mathrm{L}$, respectively. The Chromatograms were recorded at 227 and $280 \mathrm{~nm}$, using GR and SFN authentic standard, respectively (Phytoplan, Germany), as external standard. 


\subsection{UHPLC-ESI-QqQ-MS/MS analysis of beer}

The SFN present in broccoli-supplemented beer were resolved chromatographically and identified as defined by Baenas et al. (2017), on a ZORBAX Eclipse Plus C-18 Rapid Resolution HD $(2.1 \times 50$ mm, $1.8 \underline{\mu} \mu m)$ (Agilent Technologies). The beer samples were filtered with PVFD syringe filters $(0.22 \mu \mathrm{m}$ pore-size, $13 \mathrm{~mm}$ diameter, Waters Corporation, US). Sulforaphane was detected using Multiple Reaction Monitoring (MRM) transitions by a UHPLCESI-QqQ-MS/MS method (Agilent Technologies, Waldbronn, Germany) (Dominguez-Perles et al., 2014). The mobile phases were deionized-water/ammonium acetate $13 \mathrm{mM}(\mathrm{pH} 4)$ (99.99:0.01, v/v) (solvent A) and acetonitrile/acetic acid (99.99:0.1, v/v) (solvent B). The chromatographic separation of SFN was achieved by applying the following linear gradient (time (minutes), \%B), (0, 1\%); (0.7, 60\%); (0.71, 73\%); (1.00, 73\%); (1.01, 100\%); and (3.50, 100\%). The flow rate and volume of injection were $0.3 \mathrm{~mL} / \mathrm{min}$ and $10 \underline{\mu} \mu \mathrm{L}$, respectively. Data acquisition was performed using MassHunter software version B.08.00 (Agilent). The concentrations of GR and SFN were calculated from the area ratio of the ion peaks of the compounds to those of the authentic standards.

\subsection{Descriptive sensory analysis}

The descriptive sensory analysis of broccoli beer was performed by ten judges of an expert panel (aged 25-45 years; 5 males and 5 females) trained during more than 500h in sensory testing from the Department of Agro-Food Technology of Miguel Hernández University of Elche (Orihuela, Alicante, Spain).

Two preliminary orientation sessions were realized to discuss the attributes considered by the panelist that describe the beers. The study was conducted in a normalized testing room $\left(20 \pm 2{ }^{\circ} \mathrm{C}\right)$ with a combination of natural and no-natural (fluorescent) light and samples were served in odor-free glasses (Andreu-Sevilla et al.; Vivek et al., 2020).

The panelists used a numerical scale for the intensity of each attribute: 0 (no intensity) to 10 (extremely strong), with changes of 0.5 units. The attributes of sensory profile (visual and flavor parameters) in the broccoli beers were defined in previous works (Zapata et al., 2019).

\subsection{Statistical analysis}

Results are presented as means $\pm \mathrm{SD}(\mathrm{n}=3)$. A paired t-test was developed to compare two parameters, and an analysis of variance (ANOVA) and Tukey's multiple range tests were carried out to compare three or more conditions. All statistical analyses were performed using SPSS 25.0 software (LEAD Technologies, Inc., Chicago, IL, USA). The level of statistical significance was set at $p<0.05$.

\section{Results and discussion}

\subsection{Changes in the quality parameters of the beer due to the supplementation with broccoli heads}

Taking into account the previous results obtained by the testing panel, a beer similar to the typical pale ale was obtained, but with a more malty and caramelized character. The beer had 20 IBUs (International Bitterness Unit) and the color had 20 EBC (European Brewery Convention), so the beer was within the typical range of this style, as well as in its alcoholic graduation, 5.5\% ABV (Alcohol By Volume).

Broccoli beer showed statistically significant differences on $\mathrm{pH}$, acidity, alcohol content, bitterness and color EBC with respect to control beer, but not significant effects were observed on total soluble solids. Alcohol content increased with the addition of broccoli to the beer with respect to control beer (Table 1). This is in accordance to previous works where the addition of quince (Zapata et al., 2019) or goji berries (Ducruet et al., 2017) to the beer augmented the alcoholic grade, as during the time of maceration a second fermentation occurs, due to the sugar contribution of fruit and vegetables. Moreover, higher $\mathrm{pH}$ and acidity values were obtained in broccoli-supplemented beers with respect to control ones. 
Physico-chemical parameters of beer.

\begin{tabular}{|l|l|l|l|}
\hline Parameter & Control beer & Broccoli-supplemented beer & $*$-value \\
\hline $\mathrm{pH}$ & $4.21 \pm 0.01$ & $4.32 \pm 0.01$ & $* * *$ \\
\hline Total soluble solids (Brix) & $5.61 \pm 0.03$ & $5.58 \pm 0.02$ & $* * *$ \\
\hline Acidity (\%) & $0.53 \pm 0.004$ & $0.57 \pm 0.006$ & $* *$ \\
\hline Alcoholic grade (\%) & $5.64 \pm 0.02$ & $5.77 \pm 0.03$ & $* * *$ \\
\hline Ibus bitter (IBUs) & $19.5 \pm 0.11$ & $18.3 \pm 0.13$ & $* *$ \\
\hline Color (EBC) & $19.9 \pm 0.21$ & $18.7 \pm 0.18$ & $* *$ \\
\hline
\end{tabular}

$\mathrm{NS}=$ not significant at $\mathrm{p}<0.05 ; * *$ and $* * *$ significant at $\mathrm{p}<0.01$ and 0.001 respectively. Values are the mean of three replicates $\pm \mathrm{SE}$.

N.s., not significant. EBC, European Brewing Convention.

Conversely, the bitterness of the broccoli-supplemented samples (18.3 IBUs) was lower than in control beer (19.5 IBUs). On the other hand, significant differences were also found in color (an important characteristic of beer, giving information about its style) obtained by EBC, being higher in control beers, although both were values in the typical range of the style pale ale.

\subsection{Glucoraphanin and sulforaphane composition of the developed broccoli-supplemented beer}

Simultaneously to the production of the broccoli-supplemented beer, the fresh broccoli heads content of GR and SFN was analyzed by HPLC according to the methodology previously described. This characterization revealed a high concentration of GLS, mainly represented by GR found at a concentration of $73.25 \mu \mathrm{mol} / \mathrm{L}$ (Fig. 1), which was in agreement with previously description in the literature published data (Alvarez-Jubete et al., 2014; Wei et al., 2020). However, SFN resulting from the enzymatic hydrolysis of GR was almost absent in the plant material. This fact is in agreement with previous characterizations of brassicas-plant material because of the reactions needed to the hydrolysis of GLS to give rise ITCs, which are prevented in intact plant material where the enzyme responsible for catalyzing such reaction remains in different cell compartments than the reaction's substrate (GLS) (Baenas et al., 2017; Li et al., 2017).

alt-text: Fig. 1

Fig. 1

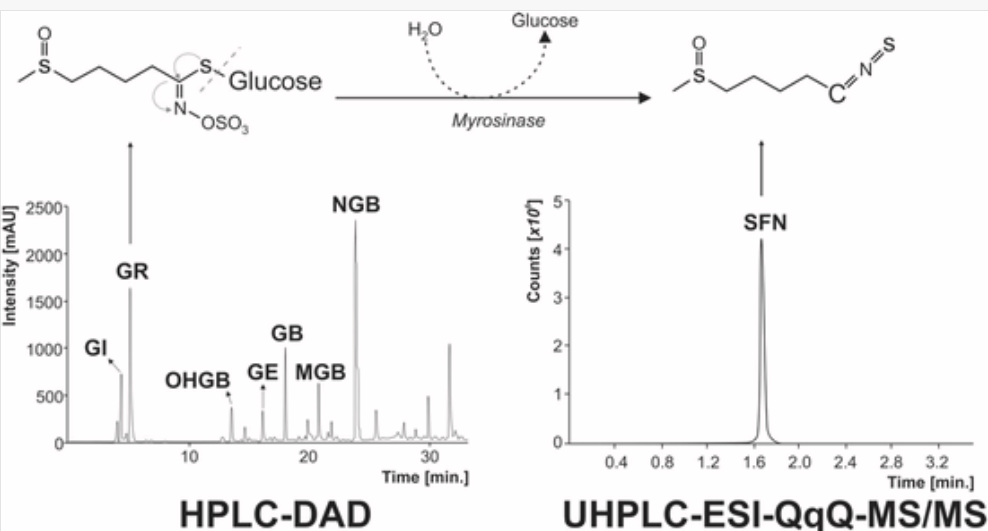

Representative chromatogram of broccoli florets glucosinolates and GR (HPLC-DAD) and SFN (UHPLC-ESI-QqQ-MS/MS) obtained by the myrosinase hydrolisis. GI, Glucoiberin; GR, Glucoraphanin; HGR, 4-Hidroxyglucobrassicin; GE, Glucoerucin; GB, Glucobrassicin; MGB, Methoxyglucobrassicin; NGB, Neoglucobrassicin; SFN, sulforaphane.

Nevertheless, the analysis of the supplemented beer evidenced the absence of GR in these new beverages (the same as in control samples), while SFN was present, in high concentration, in all samples collected during the three consecutive days, when broccoli heads were maintained macerating in the beer (BRA, $0.09 \mu \mathrm{mol} / \mathrm{L}$; BRA1, $11.37 \mu \mathrm{mol} / \mathrm{L}$; BRA2, 
$12.02 \mu \mathrm{mol} / \mathrm{L}$; BRA3, $18.85 \mu \mathrm{mol} / \mathrm{L}$ ) (Fig. 2). No SFN was detected in the control beer. These concentrations are in good agreement with other similar brassica-based foods previously studied, like broccoli juice treated with high pressures, heat or electric pulses, resulting in concentrations of SFN in the range 43.9-50.1 $\mu \mathrm{mol} / \mathrm{L}$ (Totušek et al., 2011). In this regard, also, other experimental juice control reported concentration of $19.3 \mu \mathrm{mol} / \mathrm{L}$ (MartínezHernández et al., 2019). However, to compare rationally these data, with those retrieved regarding the newly developed broccoli-supplemented beer, the physico-chemical differences between these food matrices, in terms of $\mathrm{pH}$, temperatures during the manufacturing process, composition, and especially the presence of yeast and alcohol in the beer, should be taken into consideration.

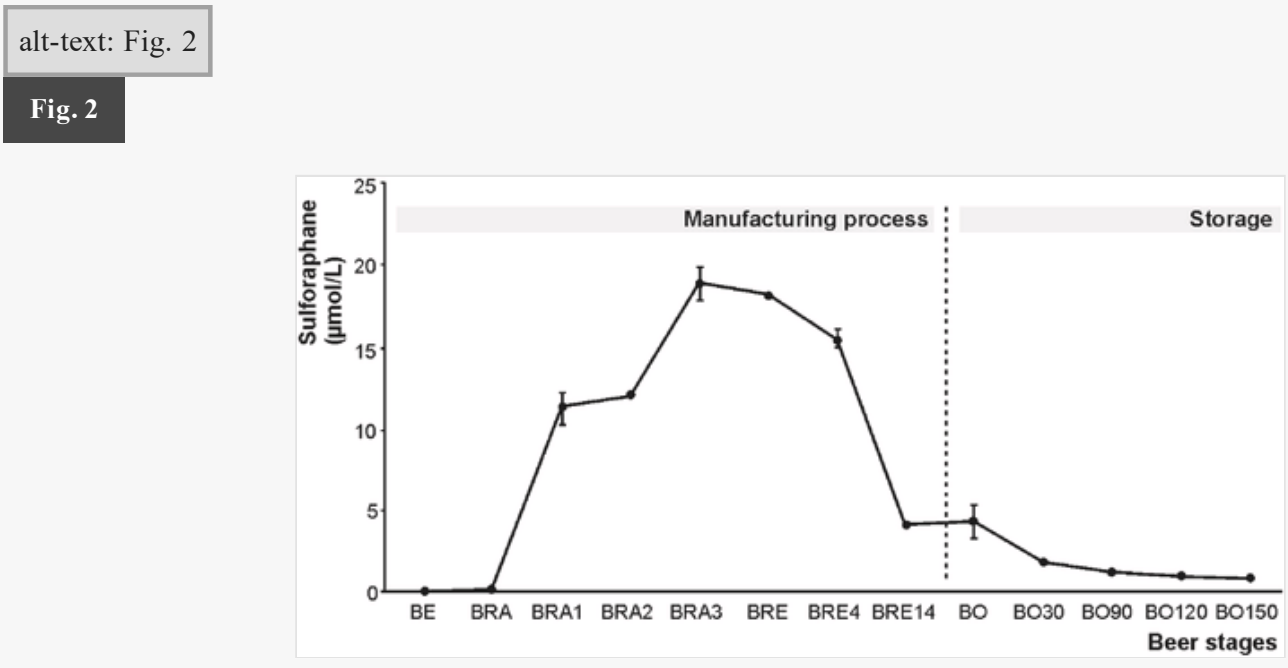

Concentration of SFN $(\mu \mathrm{mol} / \mathrm{L})$ in the broccoli-supplemented beer, in the different experimental steps: BE, beer elaboration; BRA, Broccoli Addition; BRA1, Broccoli Addition day 1; BRA2, Broccoli Addition day 2; BRA3, Broccoli Addition day 3; BRE, Broccoli retirement; BRE4, Broccoli Retirement day 4; BRE14, Broccoli Retirement day 14; BO, Bottling; BO30, Bottling day 30; BO90, Bottling day 90; BO120, Bottling day 120; BO150, Bottling day 150.

As mentioned above, in this work, a concentration of $73.25 \mu \mathrm{mol} / \mathrm{L}$ of GR was detected in broccoli heads. According to the procedure described in the literature, this content was considered as a reference to calculate the relative transformation of GR leached to beer from the original broccoli heads during its supplementation (Dominguez-Perles et al., 2011), and the relative transformation of GR into SFN in the beer. Hence, according to the concentration of GR and SFN in broccoli heads and broccoli-supplemented beer (73.25 and $18.85 \mu \mathrm{mol} / \mathrm{L}$, respectively), GR did not leach totally into beer, while the compounds getting into the newly developed beer were transformed immediately into SFN, that constitutes approximately $25 \%$ of the GR concentration in broccoli heads $(\mathrm{w} / \mathrm{v})$.

The generation of SFN is produced as a consequence of the hydrolysis of the glucoside moiety present in the GR molecule, by action of the myrosinase enzyme, a $\beta$-thioglucosidase responsible for such hydrolysis reaction (Andini et al., 2020; Zhang et al., 2020). Otherwise, myrosinase enzyme is located in the vacuole of the cell, and requires cell damage to be released (i.e., caused by cutting or chopping) (Baenas et al, 2017, 2020; Wei et al., 2020). In this sense, an array of factors modulates the myrosinase activity, like $\mathrm{pH}$, temperature, or the presence of co-factors. Optimal $\mathrm{pH}$ for the maximum myrosinase activity varies between 6 and 7. The $\mathrm{pH}$ of the newly developed beer was 4.3, which implies certain acidity that could contribute to cause an osmotic shock in plant cells, liberating more GR and myrosinase, and thus promoting the conversion of GR into SFN (Sugiyama \& Hirai, 2019). Regarding the optimal temperature for the enzymatic activity of myrosinase, this has been reported between 20 and $30{ }^{\circ} \mathrm{C}$ (Ludikhuyze et al., 2000), while lower temperatures would improve the stability of SFN during conservation (Cai et al., 2019). The supplementation of beer, with broccoli-heads, was performed at $10{ }^{\circ} \mathrm{C}$ during 3 days, and the conservation after bottling was set up at room temperature $\left(25-30^{\circ} \mathrm{C}\right)$.

An additional fact that could be modulating the transformation of GLS into its bioactive ITC in the beer matrix could be the level of free iron, since myrosinase is featured by an enzymatic activity dependent on the free iron $\left(\mathrm{Fe}^{2+}\right.$ and $\left.\mathrm{Fe}^{3+}\right)$ concentration, as a potential cofactor of the epithiospecifier protein (Williams et al., 2010). Based on this premise, the availability of iron to myrosinase in beer could be liable for a boosted transformation of GR into SFN in this newly developed beer. Thus, as a result, the combination of broccoli heads with beer gave rise to a new beverage with an interesting concentration of SFN that are naturally absent in this beverage. 
Besides the factors responsible for the activity level of broccoli myrosinase, recently, myrosinase-positive bacteria have been characterized regarding a molecular mechanism to convert GLS into its respective ITC by a $\beta$-glucosidase-like activity, which can interact with the $\beta$-D-thioglucose present in GR and other GLS (Albaser et al., 2016). In this regard, yeasts species typically employed in beer production, like Brettanomyces and some Saccharomyces, have been described as presenting $\beta$-glucosidase activity as a part of their metabolic tools (Serra Colomer et al., 2019).

\subsection{Permanence of sulforaphane in broccoli-supplemented beer during short-term storage}

Three days after the supplementation of beer, the broccoli heads were removed and the concentration of SFN was monitored during the following phases of beer manufacturing. In this period, the concentration of SFN in the broccolisupplemented beer decreased from the maximum concentration reached after 3 days of maceration in beer (18.85 $\mu \mathrm{mol} / \mathrm{L}$, on average) (Fig. 2, BRA3). Concerning this, the retirement of the broccoli heads from the beer (BRE) did not show significant variations of the SFN concentration $(18.18 \mu \mathrm{mol} / \mathrm{L})$ relative to the last elaboration step (BRA3), possibly due to the limited time elapsed (Fig. 2). Nevertheless, after 4 and 14 days (BRE4 and BRE14, respectively) the SFN concentration decreased by $17.9 \%$ and $78.1 \%$, respectively, in comparison with BRA3.

Afterward, broccoli supplemented beers were bottled and the concentration of SFN was determined during postbottling storage during 150 days, at room temperature. After bottled, the SFN concentration was determined at day 0 (BO0, $4.28 \mu \mathrm{mol} / \mathrm{L}$ ) showing no significant differences with the last determination prior to bottled. The evaluation of then SFN stability in broccoli-supplemented beers during storage evidenced that its content lowered significantly between the day 0 and day 30 (BO30, $1.83 \mu \mathrm{mol} / \mathrm{L}$ ). This period resulted in losing $57.2 \%$ of SFN. Subsequently, the SFN concentration moderated the loss of SFN until day 90 of storage (BO90, $1.16 \mu \mathrm{mol} / \mathrm{L}$ ), during this period it was recorded a $31.6 \%$ loss relative to $\mathrm{BO} 30$. At day 120 of storage (BO120) the beers assessed exhibited a $15.5 \%$ lower concentration of SFN $(0.98 \mu \mathrm{mol} / \mathrm{L})$ in comparison with BO90. Finally, at the end day considered for evaluating stability of SFN during storage (BO150) the concentration drop an additional $18.4 \%$ relative to the previous time-point. However, despite $95.8 \%$ of SFN loss of SFN during storage for 150 days in broccoli-supplemented beer, in comparison with the highest concentration peak recorded during the addition of broccoli (BRA3), could seem disheartening, even so, this implies a valuable concentration of SFN $(0.80 \mu \mathrm{mol} / \mathrm{L})$ after whole storage period in the newly developed broccoli-supplemented beer, especially when compared with previous studies, which elaborated beverages as a dietary sources of this bioactive ITC, evidencing the difficulty of conserving SFN in liquid matrices like broccoli juice. In this regard, this previous work by Martínez-Hernández et al. (2019) observed the total loss of SFN after $24 \mathrm{~h}$ in broccoli juice.

\subsection{Acceptance of the new developed broccoli beer}

Twenty-four attributes involved in the visual and flavor were used to fully describe the beers and are presented in Table 2. The sensory profile indicated that significant differences were found in all attributes evaluated. The addition of broccoli provided highest intensity of floral, fruity, herbal, cooked vegetable and early-leather attributes. However, these beers were characterized by lowest intensity of caramel, malta-buscuit, grain cereal, hop and toasted comparing to the control beer. Moreover, panelists decreased the perception of color and bitterness in broccoli beer, and these results were according to the physico-chemical results obtained. Floral attribute was also predominated in beers elaborated with other fruits such as quince which had a similar sensory profile (Zapata et al., 2019). However, the addition of broccoli in the beers increased the herbal notes characteristics of this vegetable. Sensory results showed that this new broccoli beer could have good acceptance by consumers due to the noticeable herbal and florasinsl notes.

alt-text: Table 2

Table 2

(i) The table layout displayed in this section is not how it will appear in the final version. The representation below is solely purposed for providing corrections to the table. To preview the actual presentation of the table, please view the Proof.

Descriptive sensory analysis of control and broccoli beer. The intensity scale used range from 0 (no intensity) to 10 (high intensity). 


\begin{tabular}{|c|c|c|c|}
\hline Color & $6.400 \pm 0.059$ & $5.800 \pm 0.046$ & $* * *$ \\
\hline Foam persistence & $7.300 \pm 0.078$ & $7.500 \pm 0.082$ & $*$ \\
\hline \multicolumn{4}{|l|}{ Flavor } \\
\hline Malta-biscuit & $7.200 \pm 0.054$ & $2.100 \pm 0.071$ & $* * *$ \\
\hline Grain cereal & $6.900 \pm 0.069$ & $2.400 \pm 0.087$ & $* * *$ \\
\hline Toasted & $4.300 \pm 0.025$ & $1.200 \pm 0.056$ & $* * *$ \\
\hline Caramel & $5.200 \pm 0.063$ & $1.600 \pm 0.071$ & $* * *$ \\
\hline Nuts & $2.900 \pm 0.015$ & $0.900 \pm 0.026$ & $* * *$ \\
\hline Bitter almond & $2.800 \pm 0.017$ & $1.100 \pm 0.032$ & $* * *$ \\
\hline Hop & $4.700 \pm 0.024$ & $1.800 \pm 0.030$ & $* * *$ \\
\hline Floral & $4.200 \pm 0.081$ & $6.800 \pm 0.079$ & $* * *$ \\
\hline Fruity & $2.100 \pm 0.015$ & $4.700 \pm 0.021$ & $* * *$ \\
\hline Herbal & $1.800 \pm 0.031$ & $9.100 \pm 0.021$ & $* * *$ \\
\hline Cooked vegetable & $0.700 \pm 0.020$ & $9.300 \pm 0.027$ & $* * *$ \\
\hline Yeast & $3.700 \pm 0.061$ & $0.700 \pm 0.056$ & $* * *$ \\
\hline Earthy-leather & $1.800 \pm 0.052$ & $6.900 \pm 0.121$ & $* * *$ \\
\hline Alcoholic & $3.600 \pm 0.084$ & $5.700 \pm 0.064$ & $* * *$ \\
\hline Sweet & $6.800 \pm 0.110$ & $4.700 \pm 0.053$ & $* * *$ \\
\hline Sour & $5.800 \pm 0.094$ & $5.100 \pm 0.057$ & $* * *$ \\
\hline Bitter & $6.900 \pm 0.083$ & $2.500 \pm 0.093$ & $* * *$ \\
\hline Astringent & $3.800 \pm 0.026$ & $3.500 \pm 0.031$ & $* * *$ \\
\hline Heat & $1.800 \pm 0.011$ & $1.900 \pm 0.010$ & $* * *$ \\
\hline Spicy & $3.100 \pm 0.056$ & $2.700 \pm 0.034$ & $* * *$ \\
\hline Body & $3.500 \pm 0.038$ & $4.800 \pm 0.041$ & $* * *$ \\
\hline Aftertaste & $5.700 \pm 0.023$ & $4.200 \pm 0.028$ & $* * *$ \\
\hline
\end{tabular}

Values are the mean of three replicates \pm SE. Significant differences between beers at $p<0.05$ and $p<0.001(*$ and $* * *$, respectively) according to unpaired $t$-test.

\subsection{Acceptance of the new developed broccoli beer}

Sensory profile of broccoli and control beers and the list of the main sensory attributes used in the description of the beers, are shown in Table 2. Significant differences were found in all sensory attributes evaluated. Broccolisupplemented beer had the highest intensity of floral, fruity, herbal, cooked vegetable, and earthy-leather sensory attributes and the lowest intensity of caramel, malta-biscuit, grain cereal, hop, and toasted attributes as compared to the control beer. The addition of broccoli decreased the perception of color and bitterness by the trained panel, and these results are according to the physico-chemical results obtained. The floral attribute also predominated in beers elaborated with other fruits such as quince which had a similar sensory profile (Zapata et al., 2019). However, the herbal attribute has stood out in this type of beer due to the addition of broccoli. Sensory data proved that the broccoli beers studied had appropriate sensory characteristics that should lead to good consumer acceptance (based on recognizable intensities of key herbal and floral notes in the beers).

\section{Conclusions}


Broccoli beer can be an alternative for nutritional beers development, as their organoleptic properties could be well accepted and attractive for the consumers. This work showed the conversion of GRA into its functional isothiocyanate, SFN, in a broccoli-supplemented novel beer, as well as the SFN behavior during the different elaboration steps of the beer. The assessment of SFN stability during storage, the beer matrix allowed to stability a valuable SFN content in the beer, during 150 days of post-bottling conservation. These results involve a newly application of broccoli material addressed to achieving new products that constitute a valuable dietary source of bioactive compounds. Regarding to this, other plant materials could be explored for the brewing alternative novel beers, with different nutritional and bioactive properties, in order to address the demand of the agro-food and health markets.

\section{Q4 Uncited references}

Andreu-Sevilla et al., 2013.

\section{CRediT authorship contribution statement}

Ángel Abellán: Investigation. Raúl Domínguez-Perles: Validation, Writing - original draft. María José Giménez: Investigation, Writing - original draft. Pedro J. Zapata: Conceptualization, Resources, Supervision. Daniel Valero: Resources, Writing - review \& editing, Supervision. Cristina García-Viguera: Conceptualization, Writing - review \& editing, Visualization, Supervision.

\section{Declaration of competing interest}

No conflict of Interest.

\section{Acknowledgements}

Q3 AAV was supported by INBAUTEK SL enterprise (Murcia, Spain). Research Group "Food Quality and Safety" of University Miguel Hernández for technical support in sensory evaluation.

\section{References}

(i) The corrections made in this section will be reviewed and approved by a journal production editor. The newly added/removed references and its citations will be reordered and rearranged by the production team.

Abellán, Á., Domínguez-Perles, R., Moreno, D.A., \& García-Viguera, C. (2019). Sorting out the value of cruciferous sprouts as sources of bioactive compounds for nutrition and health. Nutrients, 11, 429.

Albaladejo, M., Guo, F., Hidalgo-Duque, C., Yeom, S., Lee, D., \& Son, J.-Y., et al. (2017). Discriminant analysis classification of different types of beer according to their colour characteristics. Journal of Physics: Conference Series, 794.

Albaser, A., Kazana, E., Bennett, M., Cebeci, F., Luang-In, V., \& Spanu, P., et al. (2016). Discovery of a bacterial glycoside hydrolase family 3 (GH3) $\beta$-glucosidase with myrosinase activity from a Citrobacter strain isolated from soil. Journal of Agricultural and Food Chemistry, 64.

Alvarez-Jubete, L., Valverde, J., Kehoe, K., Reilly, K., Rai, D.K., \& Barry-Ryan, C. (2014). Development of a novel functional soup rich in bioactive sulforaphane using broccoli (Brassica oleracea L. ssp. italica) florets and byproducts. Food and Bioprocess Technology, 7, 1310-1321.

Andini, S., Araya-Cloutier, C., Sanders, M., \& Vincken, J.-P. (2020). Simultaneous analysis of glucosinolates and isothiocyanates by reversed-phase ultra-high-performance liquid chromatography-electron spray ionizationtandem mass spectrometry. Journal of Agricultural and Food Chemistry, 68, 3121-3131.

Andreu-Sevilla, A.J., Mena, P., Martí, N., García Viguera, C., \& Carbonell-Barrachina, Á.A. (2013). Volatile composition and descriptive sensory analysis of pomegranate juice and wine. Food Research International, 54, 246-254. 
Baenas, N., Cartea, M.E., Moreno, D.A., Tortosa, M., \& Francisco, M. (2020). Chapter 6 - processing and cooking effects on glucosinolates and their derivatives. Academic Press.

Baenas, N., Gómez-Jodar, I., Moreno, D.A., García-Viguera, C., \& Periago, P.M. (2017). Broccoli and radish sprouts are safe and rich in bioactive phytochemicals. Postharvest Biology and Technology, 127, 60-67.

Baenas, N., Marhuenda, J., García-Viguera, C., Zafrilla, P., \& Moreno, D.A. (2019). Influence of cooking methods on glucosinolates and isothiocyanates content in novel cruciferous foods. Foods, 8, 257.

Bellut, K., Michel, M., Zarnkow, M., Hutzler, M., Jacob, F., \& Lynch, K.M., et al. (2019). On the suitability of alternative cereals, pseudocereals and pulses in the production of alcohol-reduced beers by non-conventional yeasts. European Food Research and Technology, 245, 2549-2564.

Bertuzzi, T., Mulazzi, A., Rastelli, S., Donadini, G., Rossi, F., \& Spigno, G. (2020). Targeted healthy compounds in small and large-scale brewed beers. Food Chemistry, 310, 125935.

Cai, Y.X., Wang, J.H., McAuley, C., Augustin, M.A., \& Terefe, N.S. (2019). Fermentation for enhancing the bioconversion of glucoraphanin into sulforaphane and improve the functional attributes of broccoli puree. Journal of Functional Foods, 61, 103461.

Capece, A., Romaniello, R., Siesto, G., \& Romano, P. (2018). Conventional and non-conventional yeasts in beer production. 4,38 .

Caporale, G., \& Monteleone, E. (2004). Influence of information about manufacturing process on beer acceptability. Food Quality and Preference, 15, 271-278.

Carvalho, N., Minim, L., Nascimento, M., Ferreira, G., \& Minim, V. (2018). Characterization of the consumer market and motivations for the consumption of craft beer. British Food Journal, 120(2), 378-391.

Dimitrić Marković, J.M., Pejin, B., Milenković, D., Amić, D., Begović, N., Mojović, M., \& Marković, Z.S. (2017). Antiradical activity of delphinidin, pelargonidin and malvidin towards hydroxyl and nitric oxide radicals: The energy requirements calculations as a prediction of the possible antiradical mechanisms. Food Chemistry, $218,440-446$.

Dominguez-Perles, R., Medina, S., Moreno, D.Á., García-Viguera, C., Ferreres, F., \& Gil-Izquierdo, Á. (2014). A new ultra-rapid UHPLC/MS/MS method for assessing glucoraphanin and sulforaphane bioavailability in human urine. Food Chemistry, 143, 132-138.

Dominguez-Perles, R., Moreno, D.A., Carvajal, M., \& Garcia-Viguera, C. (2011). Composition and antioxidant capacity of a novel beverage produced with green tea and minimally-processed byproducts of broccoli. Innovative Food Science \& Emerging Technologies, 12, 361-368.

Domínguez-Perles, R., Moreno, D.A., \& García-Viguera, C. (2012). Analysis of the tumoral cytotoxicity of green tea-infusions enriched with broccoli. Food Chemistry, 132, 1197-1206.

Ducruet, J., Rébénaque, P., Diserens, S., Kosińska-Cagnazzo, A., Héritier, I., \& Andlauer, W. (2017). Amber ale beer enriched with goji berries - the effect on bioactive compound content and sensorial properties. Food Chemistry, 226, 109-118.

Francisco, M., Moreno, D.A., Cartea, M.E., Ferreres, F., García-Viguera, C., \& Velasco, P. (2009). Simultaneous identification of glucosinolates and phenolic compounds in a representative collection of vegetable Brassica rapa. Journal of Chromatography A, 1216, 6611-6619.

Gresser, A. (2009). Properties and quality. Eßlinger.

Humia, B.V., Santos, K.S., Barbosa, A.M., Sawata, M., \& Mendonça, M.d.C., et al. (2019). Beer molecules and its sensory and biological properties: A review. Molecules, 24, 1568.

Humia, B.V., Santos, K.S., Schneider, J.K., Leal, I.L., de Abreu Barreto, G., \& Batista, T., et al. (2020). Physicochemical and sensory profile of Beauregard sweet potato beer. Food Chemistry, 312, 126087. 
Koh, E., Wimalasiri, K.M.S., Chassy, A.W., \& Mitchell, A.E. (2009). Content of ascorbic acid, quercetin, kaempferol and total phenolics in commercial broccoli. Journal of Food Composition and Analysis, 22, 637643.

Kyselová, L., \& Brányik, T. (2015). 20 - quality improvement and fermentation control in beer. Woodhead Publishing.

Li, R., Song, D., Vriesekoop, F., Cheng, L., Yuan, Q., \& Liang, H. (2017). Glucoraphenin, sulforaphene, and antiproliferative capacity of radish sprouts in germinating and thermal processes. European Food Research and Technology, 243, 547-554.

López-Chillón, M.T., Baenas, N., Villaño, D., Zafrilla, P., Cristina, G.-V., \& Moreno, D.A. (2018). Broccoli for food and health - research and challenges. Acta Horticulturae, 121-126. doi:10.17660/ActaHortic.2018.1202.18.

Ludikhuyze, L., Rodrigo, L., \& Hendrickx, M. (2000). The activity of myrosinase from broccoli (Brassica oleracea L. cv. Italica): Ifluence of intrinsic and extrinsic factors. Journal of Food Protection, 63, 400-403.

Martínez-Hernández, G.B., Venzke-Klug, T., Carrión-Monteagudo, M.d.M., Artés Calero, F., López-Nicolás, J.M., \& Artés-Hernández, F. (2019). Effects of $\alpha$-, $\beta$ - and maltosyl- $\beta$-cyclodextrins use on the glucoraphaninsulforaphane system of broccoli juice. Journal of the Science of Food and Agriculture, 99, 941-946.

Md Salim, N.S., Garièpy, Y., \& Raghavan, V. (2019). Effects of processing on quality attributes of osmo-dried broccoli stalk slices. Food and Bioprocess Technology, 12.

Papazian, C. (2009). Beer styles: Their origins and classification. (Graham G).

Ramirez, D., Abellán-Victorio, A., Beretta, V., Camargo, A., \& Moreno, D.A. (2020). Functional ingredients from Brassicaceae species: Overview and perspectives. 21, 1998.

Serra Colomer, M., Funch, B., \& Forster, J. (2019). The raise of Brettanomyces yeast species for beer production. Current Opinion in Biotechnology, 56, 30-35.

STATISTA. Beer market in Spain dossier. Available from https://es.statista.com, 2020. Accesed on May 2020.

Sugiyama, R., \& Hirai, M.Y. (2019). Atypical myrosinase as a mediator of glucosinolate functions in Plants. Frontiers of Plant Science, 10. 1008-1008.

Totušek, J., Triska, J., Lefnerova, D., Strohalm, J., Vrchotova, N., Zendulka, O., ... Houška, M. (2011). Contents of sulforaphane and total isothiocyanates, antimutagenic activity, and inhibition of clastogenicity in pulp juices from cruciferous plants. Czech Journal of Food Sciences, 29, 548-556.

Vera, L., Aceña, L., Guasch, J., Boqué, R., Mestres, M., \& Busto, O. (2011). Characterization and classification of the aroma of beer samples by means of an MS e-nose and chemometric tools. Analytical and Bioanalytical Chemistry, 399, 2073-2081.

Vivek, K., Subbarao, K.V., Routray, W., Kamini, N.R., \& Dash, K.K. (2020). Application of fuzzy logic in sensory evaluation of food products: A comprehensive study. Food and Bioprocess Technology, 13, 1-29.

Wei, L., Liu, C., Zheng, H., \& Zheng, L. (2020). Melatonin treatment affects the glucoraphanin-sulforaphane system in postharvest fresh-cut broccoli (Brassica oleracea L.). Food Chemistry, 307, 125562.

Williams, D.J., Critchley, C., Pun, S., Chaliha, M., \& O'Hare, T.J. (2010). Key role of $\mathrm{Fe}^{2+}$ in epithiospecifier protein activity. Journal of Agricultural and Food Chemistry, 58, 8512-8521.

Zapata, P.J., Martínez-Esplá, A., Gironés-Vilaplana, A., Santos-Lax, D., \& Noguera-Artiaga, L., et al. (2019). Phenolic, volatile, and sensory profiles of beer enriched by macerating quince fruits. LWT, 103, 139-146.

Zhang, S., Ying, D.Y., Cheng, L.J., Bayrak, M., Jegasothy, H., \& Sanguansri, L., et al. (2020). Sulforaphane in broccoli-based matrices: Effects of heat treatment and addition of oil. LWT-Food Science and Technology, 128, 